\title{
Supremo Tribunal Federal e a naturalização da barbárie
} The Brazilian Federal Supreme Court and the normalization of barbarity

Ana Flauzina ${ }^{1}$

1 Universidade Federal da Bahia, Salvador, Bahia, Brasil. E-mail: anaflauzina@yahoo.com.br. ORCID: https://orcid.org/0000-0002-9995-7675.

Thula Pires ${ }^{2}$

2 Pontifícia Universidade Católica do Rio de Janeiro, Rio de Janeiro, Rio de Janeiro, Brasil. E-mail: thula@puc-rio.br. ORCID: https://orcid.org/0000-0003-2138-5483.

Artigo recebido em 18/04/2020 e aceito em 21/04/2020

\section{$(\mathrm{cc}) \mathrm{EY}$}

This work is licensed under a Creative Commons Attribution 4.0 International License. 


\title{
Resumo
}

O artigo objetiva explicitar o vocabulário jurídico-político que informa as decisões do Supremo Tribunal Federal sobre a questão prisional, atribuindo destaque às hierarquias de raça, gênero, classe e sexualidade. Busca-se evidenciar a sua atuação na reprodução do genocídio negro com impactos decisivos para as mulheres, em especial como um órgão chancelador da barbárie instalada no sistema de justiça criminal.

Palavras-chave: Racismo; Sexismo; Colonialismo Jurídico.

\section{Resumen}

El artículo tiene como objetivo explicitar el vocabulario jurídico-político que informa las decisiones de la Corte Suprema Brasileña en el tema de la prisión, dando protagonismo a las dimensiones de raza, género, clase y sexualidad. En particular, busca mostrar la acción judicial en la reproducción del genocidio negro con impactos decisivos para las mujeres y cómo la Corte Suprema actúa como canciller de la barbarie instalada en el sistema de justicia penal.

Palabras clave: Racismo; Sexismo; Colonialismo Jurídico.

\begin{abstract}
The paper aims to explain the legal-political vocabulary that informs the decisions of the Brazilian Supreme Court in a prison issue, giving prominence to the dimensions of race, gender, class and sexuality. In particular, it seeks to show the judicial action in the reproduction of the black genocide with decisive impacts for women and how the Supreme Court acts as a chancellor of barbarism installed in the criminal justice system. Keywords: Racism; Sexism; Legal Colonialism.
\end{abstract}


Introdução

Fazer uma leitura da atuação dos órgãos do sistema de justiça, notadamente do Supremo Tribunal Federal (STF), implica fundamentalmente iluminar aquilo que não se altera no percurso histórico do país. Na contramão de uma tendência que aposta na exceção como categoria analítica, há uma perspectiva negra que entende a continuidade das estruturas políticas e sociais como a melhor forma de compreensão dos fatos (WILDERSON III, 2003).

A assunção desse tipo de postura crítica requer que, de partida, explicitemos as premissas que orientam nosso olhar. Aqui, assinamos um contrato com o direito à vida e à liberdade como a métrica a pautar a temperatura da ação do Estado. Trazendo a condição específica do povo negro para o centro do debate, sustentamos que o Poder Judiciário desempenha um papel significativo na ampliação da chancela social para o aniquilamento de corpos negros, cuja dinâmica é informada por hierarquias de gênero e sexualidade que precisam ser denunciadas.

Nesse esforço de análise, empregamos a categoria genocídio em sua ampla acepção, compreendendo-a como um processo de sufocamento das comunidades negras nas mais diversas frentes de atuação institucional (FLAUZINA, 2008; VARGAS, 2010). Aqui, é necessário rememorar as dinâmicas que determinaram a eleição do racismo como pedra angular do Estado brasileiro e de suas instituições jurídico-políticas.

Com Lélia Gonzalez (1988) aprendemos que a formação histórico-cultural do Brasil produziu uma neurose que tem no racismo seu sintoma por excelência. O modelo de construção de "superioridade" do europeu sobre povos não-brancos na consolidação do projeto colonial forjou-se na experiência brasileira através de um modelo de organização (política, social, econômica e cultural) racialmente hierarquizada e estratificada. Não por acaso, "a afirmação de que todos são iguais perante a lei assume um caráter nitidamente formalista em nossas sociedades" (GONZALEZ, 1988, p. 73).

0 racismo por denegação ${ }^{1}$ explicita processos de desumanização que se perpetuam através da convivência entre institutos de igualdade jurídico-formal positivada e práticas institucionais genocidas contra corpos negros. A gramática da

\footnotetext{
${ }^{1}$ Lélia Gonzalez (1988) descreve as dinâmicas do racismo no Brasil como racismo por denegação. Para explicá-lo, resgata a categoria freudiana de denegação para configurar o processo pelo qual o indivíduo, embora formulando um de seus desejos, pensamentos ou sentimentos, até aí recalcado, continua a defender-se dele, negando que lhe pertença.
} 
exceção não se sustenta porque nos momentos considerados de estabilidade democrática a normalidade se acumpliciou com o extermínio e com os processos de morte em vida que nos foram impostos. Para os que foram racialmente estratificados na zona do não ser (FANON, 2008), a violência é a norma que sustenta o exercício da legalidade e da liberdade como atributos exclusivos para a zona do ser ${ }^{2}$.

Metodologicamente, alinhamo-nos ao feminismo ladino amefricano tal como proposto Lélia Gonzalez (1988), conferindo centralidade às permanências que a colonialidade nos impõe através de suas mais diversas matrizes de dominação (COLLINS, 2019) e à possibilidade de resgatarmos a experiência comum que a diáspora africana nos legou (GONZALEZ, 2018, p. 335-344). Ainda que mobilizemos categorias analíticas como "genocídio", "colonialidade", "zona do ser", "zona do não ser" e "amefricanidade", interessa-nos menos um trabalho sobre categorias analíticas e mais sobre realidades vividas que merecem ser compreendidas com a complexidade com que foram produzidas (CURIEL, 2020, p. 132).

Considerando esse aporte teórico-metodológico, entendemos que diferente do que foi testemunhado nos últimos trinta anos de vigência da Constituição de 1988, que manteve o modelo de convivência entre institutos formais de liberdade/igualdade e o extermínio massivo e multifatorial de gente negra, o contexto político atual apresenta novidades que merecem ser destacadas. Desde o impeachment da presidenta Dilma Rousseff em 2016, observa-se um tipo de programa nefasto que disputa a intensidade da agenda genocida em curso no país.

Se não há novidade no que tange ao animus do racismo, já que os aniquilamentos são uma constante do poder público no Brasil promovidos por todos os governos, a assunção de um projeto que celebra os extermínios traz consequências

\footnotetext{
${ }^{2}$ Tomando por influência o pensamento de Frantz Fanon (2008) e Sueli Carneiro (2005), mobilizamos os conceitos de zona do ser e zona do não ser para explicitar os processos de desumanização que marcam as relações intersubjetivas e institucionais na colonialidade. Partimos da ideia de que projeto moderno colonial europeu, de base escravista, utilizou-se da categoria raça para instituir uma separação incomensurável entre humanos (representativos do eu hegemônico que configura a zona do ser) e não humanos (aqueles que conformam a zona do não ser, geralmente referenciados como Outros). A determinação do padrão de humanidade que estrutura e é estruturada pela própria existência da zona do ser é realizada a partir do sujeito soberano ou do eu hegemônico (homem, branco, cis/hétero, cristão, proprietário e sem deficiência). Nesse sentido, e tomando em conta as engrenagens coloniais que forjaram a Améfrica Ladina, "o racismo reduz o ser a sua dimensão ôntica, negando-lhe a condição ontológica, o que the atribui incompletude humana" (CARNEIRO, 2005, p. 27). Embora estejamos falando de incomensurabilidade entre as duas zonas, entendemos que há relacionalidade entre elas, na medida em que a existência da zona do não ser é tomada como condição de possibilidade para a existência da zona do ser. A humanidade da zona do ser só pode ser vivenciada como atributo exclusivo porque sustentada na violência permanente imposta pelos mais diversos processos de desumanização sobre a zona do não ser.
} 
tangíveis e preocupantes para as comunidades negras. O que significa, numa realidade como a brasileira, a necessidade de institucionalizar (através de dimensões jurídicoformais) o genocídio? Num país em que mães dormem com a possibilidade de acordarem com suas crias despejadas em covas/celas clandestinas/institucionais, esse novo fôlego sádico não deve ser tomado como algo menor (ROCHA, 2017).

Diante esse quadro, nos parece relevante tomar assento no lugar que nos cabe e destacar o envolvimento das trincheiras jurídicas na conformação desse estado de coisas. Para tanto, propõe-se, neste artigo, uma leitura amefricana ${ }^{3}$ da atuação do STF em casos envolvendo o sistema prisional brasileiro, notadamente a partir de dois julgados: o primeiro caso, a ADPF 347-DF que reconheceu o estado de coisas inconstitucional; e, o segundo caso relacionado ao HC 143641 SP, que trata das manifestações acerca da prisão domiciliar para gestantes, puérperas, mães de crianças e mães de pessoas com deficiência, nas hipóteses do artigo 318 do Código de Processo Penal (CPP).

\section{Racismo e Sexismo na Cultura Jurídica Brasileira: uma receita de morte}

O Poder Judiciário historicamente tem sido capaz de se blindar das críticas direcionadas às suas responsabilidades na perpetuação das mazelas sociais no Brasil. A imagem de austeridade cultivada como ethos institucional, os pressupostos ilusórios da neutralidade, a aparente não associação com o mundo mais visível das movimentações políticas tradicionais fazem com que esse ramo do poder tenha ficado menos exposto do que o Executivo e o Legislativo nas análises que emergem das demandas sociais e da pesquisa acadêmica engajada.

Essa tendência vem sendo quebrada nas duas últimas décadas com uma maior visibilidade das instâncias judiciais, em especial do STF, na tomada de decisões históricas que começaram a pautar, cada vez mais, o Judiciário como poder a ser acompanhado de forma sistemática e crítica (ALVES, 2017; SANTOS, 2017; ZAFALLON, 2018).

\footnotetext{
${ }^{3}$ A categoria político-cultural da Amefricanidade foi desenvolvida por Lélia Gonzalez (2018,p. 321-334) para iluminar o processo histórico da diáspora africana na colonialidade, redimensionando o papel da influência da cultura ameríndia e africana para a formação do território que ela passou a nomear de Améfrica Ladina (no lugar de América Latina), entre resistências, aculturação e os desafios do não lugar que se apresentam nas hierarquizações subalternizadas impostas a essas heranças e sujeitos pelo legado colonial.
} 
As discussões hegemônicas sobre a atuação do Judiciário como ator político central na articulação com o Executivo e o Legislativo, assim como o papel por ele desempenhado na sustentação do Estado brasileiro, costumam tomar a Constituição de 1988 como marco temporal de análise, por supostamente ter criado condições institucionais mais favoráveis ao ativismo judicial. Partimos da hipótese de que com esse marco temporal perdemos a oportunidade de pôr em evidência como o Judiciário tem historicamente atuado enquanto um poder político e, por consequência, de analisar de que maneira o sistema de justiça tem tratado cidadãos de classes sociais, gênero, raça, sexualidade e etnias distintas em nossa sociedade.

Para entendermos como se dá a manutenção das hierarquias de humanidade entre nós através do Direito - em períodos reconhecidos como de estabilidade democrática ou não -, ao invés de tomar a Constituição de 1988 como marco temporal para pensar a atuação do Poder Judiciário, interessa-nos perceber o fenômeno a partir do advento dos cursos jurídicos no Brasil e o papel desempenhado por eles na formação do Estado Brasileiro.

Os cursos jurídicos no Brasil surgiram no contexto da independência nacional. Embora com o fim do colonialismo como regime concreto em 1822, as estruturas coloniais e as hierarquias raciais, de gênero, sexuais, culturais e econômicas foram mantidas, revestidas com a roupagem do capitalismo liberal.

A criação de cursos jurídicos foi discutida na Assembleia Constituinte de 1823 e procurou atender à demanda do Estado Nacional que se formava na lógica de um liberalismo conservador de base escravista e na conformação de uma elite própria para compor seu estamento burocrático e reproduzir a disciplina europeia (COSTA, 1992, p. 52). Os cursos que se formaram em 1827, inicialmente em São Paulo e Olinda, reproduziram a tradição acadêmica portuguesa.

O Direito brasileiro se constituiu ao longo do século XIX, de um lado, tomando como modelos constitucionais a serem perseguidos os da independência estadunidense e da revolução francesa, além de manter muitos dos institutos coloniais portugueses. De outro lado, resultou da negação da única experiência constitucional radicalmente antirracista, que foi a decorrente da revolução escrava haitiana, e que já apontava os limites das experiências e compromissos constitucionais estadunidenses e franceses do século XVIII. 
A história dos institutos jurídicos que afirmavam as liberdades públicas se desenvolveu, portanto, simultaneamente ao regime de escravidão, genocídio e exploração dos povos colonizados (QUEIROZ, 2017).

Nesse contexto, o sujeito de direito eleito representou a afirmação de uma pretendida uniformidade, forjada pela exclusão material, subjetiva e epistêmica dos povos subalternizados. A régua de proteção que determinou o padrão a partir do qual bens jurídicos passaram a ser compreendidos e tutelados derivou da afirmação da supremacia branca, masculina, cisheteronormativa, classista, cristã e inacessível às diferentes formas de ser e estar na natureza (PIRES, 2018).

Constata-se, assim, que o Direito e o sistema de justiça assumiram um papel central na formalização e na manutenção da estrutura da colonialidade, conferindo-lhe legitimidade e naturalizando seus institutos sob o signo da neutralidade. Dentro dessa dinâmica, teoria do Direito e jurisprudência passaram a consolidar os interesses dos agentes políticos hegemônicos do Estado brasileiro, excluindo do seu processo (não apenas do acesso à justiça, mas da construção normativa de forma mais ampla) aquelas (es) cuja humanidade se negava.

Considerando esse repertório de viés autoritário e excludente, a incapacidade de o Direito produzir emancipação para sujeitos, sujeitas e experiências que não são levadas em conta no processo de determinação dos bens jurídicos a serem tutelados, não pode ser simplificada em categorias como inefetividade/violação de direitos. Ao contrário, apresenta-se como a mais bem acabada forma de enunciação da legalidade como atributo exclusivo da zona do ser (PIRES, 2018).

A linha demarcatória entre a zona do ser e a zona do não ser estabelece as diferenças entre as (os) que são considerados humanas(os) e as(os) que são espoliados dessa construção nas sociedades fundadas no colonialismo. O colonizado, racializado como inferior, foi confinado a um papel social de desumanização e coisificação, mantido pela violência permanente e pelo silenciamento.

Ainda que se reconheça a complexidade e as hierarquizações internas, as(os) que habitam a zona do ser têm o reconhecimento social de sua humanidade, o acesso a direitos e a recursos materiais, bem como a consideração social de suas subjetividades, identidades, epistemologias e espiritualidades. Às(Aos) que habitam a zona do não ser, além de não serem poupados de hierarquizações internas, são negadas a humanidade e, 
por consequência, o acesso a direitos, recursos materiais e o reconhecimento de suas subjetividades, espiritualidades, epistemologias e práticas políticas.

Esse mundo cindido das zonas do ser e zona do não ser é fundamentalmente sustentado pela violência. Nesse horizonte, a gramática do Direito é indispensável na chancela dos processos de brutalização e morte dirigidos aos contingentes subalternizados, que, no Brasil, são demarcados por critérios de raça, com suas correlatas dimensões de gênero, classe e sexualidade.

Como esfera fundamental para a mobilização do Direito, o Judiciário cumpre um papel precípuo na sustentação desse estado de coisas. Por isso, é necessário quebrar o engodo de entender o Judiciário e demais órgãos do sistema de justiça como instâncias que operam a partir dos direitos humanos na tentativa de contenção frustrada da violência. Ao contrário, entendemos que as agências do controle judicial são produtoras solidárias da barbárie, sendo o papel mais perigoso desse circuito de execuções destinado aos corpos negros.

A partir dessa lente, partimos de novas bases analíticas para o questionamento do que significa ser um corpo negro julgado no Brasil. Inspiradas pelo chamamento que Beatriz Nascimento (2018) nos faz para re-orí-entação ${ }^{4}$ dos debates, levantamos algumas perguntas: A justiça brasileira tem atuado mais como garantidora dos preceitos constitucionais ou como aliada dos processos de usurpação política e social que violam a população marginalizada do país? Há que se falar em juízes ou justiceiros, ao tratarmos dos agentes institucionais que atuam a serviço da manutenção das hierarquias raciais e de gênero? As execuções sumárias e a cultura do encarceramento devem ser analisadas como atividades policiais isoladas ou justiçamentos validados por homicidas togados?

O que estamos questionando aqui é o fato de que as instituições não estão sendo capazes de realizar a missão constitucional que justifica sua existência. Assumimos o risco dessa crítica na conjuntura política atual porque não pretendemos

\footnotetext{
${ }^{4}$ Com vasta produção no campo da história, buscamos na narrativa de Beatriz Nascimento no filme Ôrí a influência para o que estamos propondo como re-orí-entação. Lançado em 1989, dirigido por Raquel Gerber, com roteiro de Maria Beatriz Nascimento, o documentário resgata a relação "transatlântica" entre o Brasil e o Continente Africano através da atuação dos movimentos negros brasileiros no período de 1977 a 1988. O título do filme - Ôrí - é buscado em uma palavra de origem yorubá que, em uma percepção amefricana, pode significar "cabeça" (seja ela física ou interior), a que guia/referencia/orí-enta, reúne intelecto/memória/pensamento, articulando presente/ passado/futuro, podendo assumir o sentido político de consciência negra. Nas palavras de Beatriz Nascimento: "ORÍ significa a iniciação a um novo estágio da vida, a uma nova vida, um novo encontro. Ele se estabelece enquanto rito e só por aqueles que sabem fazer com que uma cabeça se articule consigo mesma e se complete com seu passado, com seu presente, com seu futuro, com a sua origem e com o seu momento ali" (NASCIMENTO, 2018, p.333)
} 
continuar a ser a moeda de troca para as negociações políticas que geram maior estabilidade democrática para a zona do ser. Os órgãos do sistema de justiça precisam ser responsabilizados politicamente pelo papel que exercem na gestão do genocídio negro e na (re)produção do racismo.

Não há nesse anúncio nenhum acordo com afirmações arbitrárias - como as feitas por Eduardo Bolsonaro em palestra durante o período de campanha eleitoral de 2018, segundo as quais "para fechar o STF basta um cabo e um soldado" com narrativas que endossem medidas de enfraquecimento da correlação de forças entre os poderes constituídos. A crítica que aqui se faz não objetiva, por óbvio, somar-se a projetos que visam à dissolução das instituições como forma de legitimar autoritarismos. Ao contrário, trata-se de um chamado para que todos(as) os(as) responsáveis pela (re)produção do genocídio respondam, cada um(a) do seu lugar, pela realidade que (re)produzem. E é apenas nesse sentido - o de chamado à responsabilidade - que devem ser entendidas as análises sobre algumas decisões do STF que trataremos a seguir.

2. O que a normalização do Estado de Coisas Inconstitucional tem a informar sobre o funcionamento do sistema de justiça no Brasil?

No âmbito da Arguição de Descumprimento de Preceito Fundamental 347-DF (STF, ADPF 347-DF), o Supremo Tribunal Federal se manifestou sobre a realidade prisional brasileira ${ }^{6}$, pela primeira vez assumindo a dimensão estrutural das violências produzidas pelas condições carcerárias.

A referida ação pretendeu, entre outros pedidos específicos, o reconhecimento do estado de coisas inconstitucional. Isto é, o reconhecimento público de que se vive sobre intensa e massiva violação de direitos fundamentais das(os)

\footnotetext{
${ }^{5}$ Sobre a manifestação referenciada, ver reportagem de Rafael Vazquez e Fabio Graner no Valor Econômico de 21 de outubro de 2018. Disponível em <https://www.valor.com.br/politica/5939007/para-fechar-o-stfbasta-um-soldado-e-um-cabo-diz-eduardo-bolsonaro>, acesso em 21 de março de 2019.

${ }^{6}$ Sobre o tema da realidade prisional nacional, estão em tramitação ou foram decididas ainda as seguintes ações constitucionais: RE 580.252-MS, ADI 5.170-DF, RE 641.320-RS, ADI 5.356-MS, RE 592.581-RS. Como boa parte de seus argumentos foram retomados quando do julgamento da cautelar da ADPF 347-DF, em 2015, optamos por nos referenciar apenas a trechos dessa última decisão. Destaca-se que até a submissão deste artigo, em fevereiro de 2020, o julgamento final da ADPF 347-DF não tinha acontecido, razão pela qual o inteiro teor de que nos valemos refere-se ao julgamento da medida cautelar.
} 
presas(os), por ação ou omissão dos Poderes Públicos da União, dos Estados e do Distrito Federal.

A categoria estado de coisas inconstitucional foi consolidada pela Corte Constitucional Colombiana entre os anos de 1997 e 2004 e pretendeu categorizar situações que apresentem, ao menos, três elementos ${ }^{7}$ : (1) violação generalizada de direitos fundamentais; (2) inércia ou incapacidade reiterada e persistente das autoridades públicas em modificar a situação; (3) exigência de uma ação coordenada entre múltiplas autoridades para superação do quadro de violação de direitos (STF, ADPF 347-DF, p. 29 e p. 54).

Sobre a hipótese ser passível de aplicação ao sistema prisional brasileiro, manifestou-se o Ministro Ricardo Lewandowski: "esse estado insuportável se tornou permanente, tendo em conta ações e omissões das autoridades públicas responsáveis pelo Sistema Penitenciário Brasileiro" (STF, ADPF 347-DF, p. 29 e p.179). E reforçou o Ministro Celso de Mello em seu voto:

Há, efetivamente, no Brasil, um claro e indisfarçável "estado de coisas inconstitucional" resultante - tal como denunciado pelo PSOL - da omissão do Poder Público em implementar medidas eficazes de ordem estrutural que neutralizem a situação de absurda patologia constitucional gerada, incompreensivelmente, pela inércia do Estado que descumpre a Constituição Federal, que ofende a Lei de Execução Penal e que fere o sentimento de decência dos cidadãos desta República (STF, ADPF 347 -DF, p. 159, grifos no original).

A aplicação da referida categoria deveria representar, nos termos do voto do Ministro relator da ADPF 347-DF, Marco Aurélio Mello, as seguintes ações institucionais:

Esta arguição envolve a problemática do dever de o Poder Público realizar melhorias em presídios ou construir novos com a finalidade de reduzir o déficit de vagas prisionais. Vai além: versa a interpretação e a aplicação das leis penais e processuais de modo a minimizar a crise carcerária, implantar a forma eficiente de utilização dos recursos orçamentários que compõem o Fundo Penitenciário Nacional - FUNPEN e o dever de elaboração, pela União, estados e Distrito Federal, de planos de ação voltados a racionalizar o sistema prisional e acabar com a violação de direitos fundamentais dos presos sujeitos às condições de superlotação carcerária, acomodações insalubres e falta de acesso a direitos básicos, como saúde, educação, alimentação saudável, trabalho, assistência jurídica, indispensáveis a uma vida minimamente digna e segura (STF, ADPF 347-DF, p. 15).

\footnotetext{
7 Nesse sentido, destacam-se as seguintes decisões da Corte Constitucional da Colômbia: Sentencia no SU559, de 6 de novembro de 1997; Sentencia T-068, de 5 de março de 1998; Sentencia SU - 250, de 26 de maio de 1998; Sentencia T-590, de 20 de outubro de 1998; Sentencia T - 525, de 23 de julho de 1999; Sentencia T-153, de 28 de abril de 1998; Sentencia T-025, de 22 de janeiro de 2004.
} 
Com base nos fatos apresentados, o Ministro relator concluiu: "no sistema prisional brasileiro, ocorre violação generalizada de direitos fundamentais dos presos no tocante a dignidade, higidez física e integridade psíquica" (STF, ADPF 347-DF, p. 19). E continuou afirmando que as condições carcerárias configuram "inobservância, pelo Estado, da ordem jurídica correspondente", além de "tratamento degradante, ultrajante e indigno a pessoas que se encontram sob custódia" (Idem).

Percebe-se assim, num primeiro plano, que os apontamentos da Corte se alinham à condenação veemente das condições do sistema de justiça criminal no país. Entretanto, uma análise mais detida do julgado permite que visualizemos suas contradições.

Primeiramente, o que deveria configurar um problema em si - existência de instituições públicas que produzem tratamentos degradantes, ultrajantes e indignos - só é visto como problema quando enseja algum tipo de retorno não desejado por quem se beneficia por tamanha iniquidade, a zona do ser. No seu voto, o Ministro Luís Roberto Barroso afirma:

[...] a deficiência do sistema penitenciário reverte consequências gravíssimas e dramáticas para a própria sociedade brasileira, pela incapacidade do sistema de tratar essas pessoas com o mínimo de humanidade, o que faz com que os índices de reincidência no Brasil sejam dos mais altos do mundo" (STF, ADPF 347 -DF, p. 69).

Ao contrário do que afirma o Ministro, o problema central não é a reincidência, mas a incapacidade de que pessoas sejam reconhecidas e tratadas em sua plena humanidade fora, mas, sobretudo dentro das grades. A permanência de hierarquias de humanidade entre nós é, em si, o que pode haver de mais grave e dramático para a sociedade brasileira.

O quadro de violações que amparou a categorização do estado de coisas inconstitucional se deu a partir do reconhecimento de que:

A maior parte desses detentos está sujeita às seguintes condições: superlotação dos presídios, torturas, homicídios, violência sexual, celas imundas e insalubres, proliferação de doenças infectocontagiosas, comida imprestável, falta de água potável, de produtos higiênicos básicos, de acesso à assistência judiciária, à educação, à saúde e ao trabalho, bem como amplo domínio dos cárceres por organizações criminosas, insuficiência do controle quanto ao cumprimento das penas, discriminação social, racial, de gênero e de orientação sexual (STF, ADPF 347-DF, p. 23). 
São ainda relatadas na ADPF 347-DF, situações como a de mulheres que, diante da ausência de materiais de higiene pessoal básica, "utilizam miolos de pão para a contenção do fluxo menstrual"; de travestis que são obrigadas a se prostituir dentro das unidades; a convivência com estruturas hidráulicas, sanitárias e elétricas precárias, falta de iluminação e ventilação; áreas de banho e sol em meio a esgotos e escoamento de urina e fezes; falta de água para banho e hidratação, alimentação muitas vezes azeda ou estragada (STF, ADPF 347-DF, pp. 23 e 24).

Diante desse quadro de extrema vulnerabilidade e degradação, o julgado afirma que:

[...] A responsabilidade do Poder Público é sistêmica, revelando amplo espectro de deficiência nas ações estatais. Tem-se a denominada "falha estatal estrutural". As leis existentes, porque não observadas, deixam de conduzir à proteção aos direitos fundamentais dos presos. Executivo e Legislativo, titulares do condomínio legislativo sobre as matérias relacionadas, não se comunicam. As políticas públicas em vigor mostram-se incapazes de reverter o quadro de inconstitucionalidades. O Judiciário, ao implementar número excessivo de prisões provisórias, coloca em prática a "cultura do encarceramento", que, repita-se, agravou a superlotação carcerária e não diminuiu a insegurança social nas cidades e zonas rurais (STF, ADPF 347-DF, p. 28).

Apesar de reconhecerem a atuação de todos os poderes e praticamente todas as unidades federativas na concorrência das violações no âmbito da privação de liberdade, dos oito pedidos constantes na ADPF 347-DF, sete se dirigem à atuação do Poder Judiciário, de modo a categorizar sua necessária responsabilização pelo desrespeito sistemático e inconstitucional à manutenção da vida, integridade, saúde, acesso à educação e trabalho no cumprimento das penas.

A responsabilidade do Poder Judiciário foi afirmada no acórdão, como por exemplo, através do voto do Ministro Gilmar Mendes:

A situação de penúria do sistema prisional do país é tão notória, o que quer se diga, será expletivo e, claro, vergonhoso para todos nós. E como tenho destacado, nós não temos, no âmbito do Judiciário, sequer a desculpa de dizer que isso é culpa da Administração, porque somos administradores do sistema. Como destacou há pouco o ministro Celso, temos grande responsabilidade na mantença desse quadro caótico (STF, ADPF 347-DF, p. 137). 
Dos sete pedidos diretamente relacionados à atuação do Poder Judiciário, dois (pedidos "a" e "c") referem-se à necessidade de fundamentação das decisões que determinam a prisão, de forma a considerarem o funcionamento do sistema carcerário para as medidas anunciadas; três indicam a necessidade de aplicação da Lei de Execução Penal (LEP) e do Código de Processo Penal (CPP), que determina a aplicação de penas alternativas sempre que possível e levando-se em conta a realidade das instituições carcerárias para comutação de penas e demais medidas de execução ("d", "e", "f"); e dois relacionam-se a medidas institucionais já previstas normativamente (mutirões carcerários e audiências de custódias) com potencial de minimizar a cultura do encarceramento ("b" e "g").

Se a ADPF 347-DF tentou demonstrar o desrespeito por parte dos órgãos do Poder Judiciário na aplicação do direito positivado, em alguns votos esse argumento foi usado exatamente para negar o pedido. Conforme decisão final, por exemplo, foram negados - ainda que por decisão não unânime - os pedidos "a" ${ }^{8}$, $c$ "9 $e$ " $d$ "10 porque se a lei já obriga a que se faça o que consta no pedido, seria inócua a decisão do STF determinando a sua aplicação.

Diante da oportunidade de marcar a responsabilidade do Poder Judiciário na conformação do estado de coisas inconstitucional, a opção do STF foi a de deferir apenas dois pedidos: o primeiro relacionado à realização de audiências de custódia (hipótese vinculada a atuação do Poder Judiciário) e, o segundo, ao descontigencionamento das verbas do Fundo Penitenciário Nacional (em relação ao Executivo).

Se o Estado não é capaz de respeitar os limites normativos impostos para o cumprimento da pena, o aprisionamento deve deixar de ser usado como mecanismo de intervenção social. Entretanto, a decisão do STF omite-se no tocante a essa constatação e contorna retoricamente o centro articulador dos pedidos formulados na Ação para adotar uma saída político-jurídica que blinda o Judiciário de qualquer tipo de questionamento consequente.

8 Pedido "a", ADPF 347-DF: "aos juízes e tribunais - que lancem, em casos de determinação ou manutenção de prisão provisória, a motivação expressa pela qual não aplicam medidas cautelares alternativas à privação de liberdade, estabelecidas no artigo 319 do Código de Processo Penal".

9 Pedido " $\mathrm{C}$ ", ADPF 347 DF: "aos juízes e tribunais - que considerem, fundamentadamente, o quadro dramático do sistema penitenciário brasileiro no momento de implemento de cautelares penais, na aplicação da pena e durante o processo de execução penal".

${ }^{10}$ Pedido "d", ADPF 347 DF: "aos juízes - que estabeleçam, quando possível, penas alternativas à prisão, ante a circunstância de a reclusão ser sistematicamente cumprida em condições muito mais severas do que as admitidas pelo arcabouço normativo". 
De forma explícita, na ADPF 347-DF, o STF reconhece que os parâmetros normativos pactuados para permitir o funcionamento do sistema prisional do Brasil estão sendo violados de maneira estrutural por todos os poderes constituídos, de várias esferas federativas. O que, diante de tudo isso, permite que, ao invés de acabar com o sistema que produz essas violações, a opção seja a de fortalecê-lo? Como é próprio ao pacto narcísico ${ }^{11}$ das elites brasileiras, a falha estrutural que o sistema prisional explicita é formal, abstrata e conceitualmente enunciada apenas para sinalizar uma superficial nota de discordância. A "falência do sistema prisional" é repetida, sem que isso se converta na responsabilização dos órgãos públicos pelas violências e inconstitucionalidades que reproduzem e sustentam. Como Lélia Gonzalez (1988) nos alerta, o racismo por denegação se perpetua através da convivência entre institutos de igualdade jurídico-formal positivada e práticas institucionais genocidas contra corpos negros.

E, como há coisas que só fazem sentido para zona do ser, o Ministro Relator é capaz de, em um mesmo voto, declarar o estado de coisas inconstitucional, manter o sistema prisional em funcionamento e dizer:

Juízes e Tribunais não podem permitir que o público perda a fé na instituição "Judiciário" e no sistema de justiça penal. A credibilidade moral da justiça criminal é relevante como fator de respeito difuso às leis e às instituições e de prevenção a iniciativas de "justiça com as próprias mão" (STF, ADPF 347-DF, p. 34).

É a receita do colonialismo jurídico sendo mais uma vez aplicada, com um ou outro tempero contemporâneo. Aqui, vale lembrar que a Constituição de 1824 "proibiu o açoite" e manteve a escravidão. Em 2015, o STF reconhece o açoite que ocorre nas unidades prisionais, representado pelo estado de coisas inconstitucional, sem se dedicar às causas da sistemática violação de direitos que lá tomam assento de forma crua e brutal.

A normalização do estado de coisas inconstitucional nos impede de pensar em termos de inefetividade, exceção, seletividade ou hipocrisia moral. Estamos diante de uma realidade que institucionaliza o não acesso aos mecanismos formais de aplicação normativa para um contingente expressivo da população brasileira e que, apesar de não

\footnotetext{
11 Por influência do trabalho desenvolvido por Maria Aparecida Bento (2002) entende-se por pacto narcísico o acordo tácito entre os brancos de não se reconhecerem como parte essencial na permanência das tensões raciais e do racismo no Brasil.
} 
se restringir ao ambiente prisional, tem no cárcere a experiência exacerbada de seus efeitos.

Diante disso, o que se percebe é que a afirmação da existência do estado de coisas inconstitucional não retira do STF a responsabilidade com a sua permanência. Ao contrário, esse reconhecimento implica formalmente o STF na sua (re)produção.

Aqui, é importante destacar que além da flagrante corroboração com as estruturas instituídas do racismo e do classismo, a forma como se deu a declaração do estado de coisas inconstitucional evidencia uma especial vulnerabilidade das mulheres, cis ou trans. A normalização não nomeada da masculinidade como padrão que informa o contexto prisional (dentro das unidades e no tratamento pelo sistema de justiça dos procedimentos de execução da pena) é, portanto, um dado que precisa ser considerado. A incapacidade do STF em lidar de forma imbricada ${ }^{12} \mathrm{com}$ as violações sistemáticas que ocorrem nas unidades prisionais revela, entre outras coisas, a reprodução de um olhar institucional que reduz e reforça os estigmas sobre as pessoas que vivenciam os horrores do cárcere a partir de posicionalidades sociais que se distanciam do modelo de sujeito de direito eleito (mulheres, não brancas/os, trans, gays, lésbicas ou bissexuais, de classe popular, não cristãs/ãos, com deficiência). De forma especialmente perversa, as posturas em relação às questões de gênero afetam a vida das mulheres, em especial das mulheres negras, de forma avassaladora, conforme veremos a seguir.

\footnotetext{
12 Para definir o conceito de imbricação que perpassa esse trabalho, recorremo-nos a explicação de Ochy Curiel: “Comprender la imbricación de las opresiones [...] se trata de entender cómo estas han atravesado históricamente nuestra région desde el colonialismo hasta al colonialidad contemporânea y como se ha expresado en ciertos sujetos que no han tenido privilégios de raza, clase, sexo y sexualidad, como son las mujeres negras, indígenas y campesinas de la région" (Curiel, 2016, p.80). Trata-se de um modelo que permite compreender os efeitos estruturais e estruturantes destas categorias e como elas atravessam a experiência da colonialidade (não como marcadores identitários que se encerram em si mesmos).
} 
3. Mulheres, infâncias e prisão domiciliar: reeditando a lei do ventre livre? ${ }^{13}$

Conforme sinalizado, entendemos as implicações de gênero no âmbito das decisões do STF sobre o sistema prisional brasileiro a partir das dinâmicas do racismo e da categoria do genocídio. Nesse sentido, e em continuidade ao que já fora exposto, pretendemos nos deter sobre decisões tão festejadas quanto foi o reconhecimento do estado de coisas inconstitucional pela ADPF 347-DF, tentando iluminar como elas respondem pela continuidade das estruturas políticas e sociais de extermínio da população negra no Brasil.

No âmbito do HC 143641-SP, buscou-se a revogação da prisão preventiva decretada contra todas as gestantes, puérperas e mães de crianças até 12 anos, ou sua substituição pela prisão domiciliar. Como o compromisso do STF com a liberdade é mediado pela sua percepção da liberdade como atributo exclusivo da zona do ser, o habeas corpus deixou de ser o remédio heroico ${ }^{14}$ para produção de liberdade e acabou

\footnotetext{
${ }^{13}$ Ao assumir a enunciação de marcos históricos no contexto desse artigo, nos pautamos por perspectiva metodológica que se afina de forma íntima com os pressupostos teóricos adotados. Assim, a aproximação de eventos tais como a lei do ventre-livre e a prisão domiciliar para as mulheres gestantes e mães encarceradas está pautada na noção de continuidade dos assaltos empreendidos contra a população negra no decurso do processo histórico. Nesse sentido, Saidiya Hartman, historiadora obrigatória no tráfego negro da Diáspora, trabalha a noção de "escravidão póstuma" (afterlife of slavery), como aporte para pensar o espaço de sujeição existencial contínua das pessoas negras independentemente da aquisição da cidadania nos marcos de democracias genocidas. (HARTMAN, 1997). Desta feita, a metodologia aqui assumida entende que as distâncias espaço-temporais servem mais para aproximar do que para apartar os eventos suscitados, visto que denunciam a estrutura da dominação. Os paralelos desenhados, portanto, falam mais do padrão perene de desumanidade e abjeção a que estão submetidos os corpos negros no marco da colonialidade do que das especificidades políticas dos contextos em que estão inseridos. Para um maior aprofundamento nessa discussão ver: HARTMAN, Saidiya. Scenes of Subjection: Terror, Slavery, and SelfMaking in Nineteenth-Century America. New York, NY: Oxford University Press, 1997; WILDERSON, Frank B. Red, White, and Black: Cinema and the Structure of U.S. Antagonism. Durham, NC: Duke University Press, 2010; VARGAS, João. The Denial of Antiblackness: Multiracial Redemption and Black Suffering. Minneapolis, MN: University of Minessota Pres, 2018.

${ }^{14}$ A primeira vez que nos deparamos com a referência que a ementa do HC 143641 SP fez à doutrina brasileira do habeas corpus e, com ela, à necessidade de conferir máxima efetividade do writ, por um instante fomos tomadas pela esperança de que "máxima efetividade do habeas corpus" pudesse significar liberdade. Infelizmente e como é próprio ao colonialismo jurídico, a referida expressão representava tão somente o alargamento processual da garantia constitucional para viabilizar seu reconhecimento enquanto ação coletiva. Pode ser que, um dia, a doutrina brasileira do habeas corpus venha a representar para o Brasil e para o mundo uma experiência jurisdicional de compromisso com a liberdade e com a defesa contra toda e qualquer violação a direito fundamental, tal como descrita pelo Ministro Gilmar Mendes no seu voto no HC 143641 SP: "A fórmula básica permitia compreender o habeas corpus como um instrumento de defesa em relação a toda e qualquer lesão perpetrada pelo poder público a direito subjetivo". (STF, HC 143641 SP, p. 89). Mesmo sentido encontrado na página do STF quando se refere à doutrina brasileira do habeas corpus como "Corrente teórica encabeçada por Ruy Barbosa no final do século XIX e início do XX que, em razão da carência de remédios constitucionais, buscou ampliar as hipóteses de cabimento do habeas corpus para salvaguardar outros direitos constitucionais além do direito de ir e vir". Trecho retirado da seção "Vocabulário Jurídico (Tesauro)", disponível em <http://www.stf.jus.br/portal/jurisprudencia/listarTesauro.asp?txtPesquisaLivre=DOUTRINA\%20BRASILEIRA \%20DO\%20HABEAS\%20CORPUS>, acesso em 05 de fevereiro de 2020).
} 
se convertendo em uma grande arena de discussão sobre possibilidades de aprisionamento ou, para quem prefira, da substituição da prisão preventiva pela prisão domiciliar, nas hipóteses taxativamente previstas no CPP.

Com esse sentido reduzido pelo STF, o habeas corpus pretendeu basicamente dar aplicação ao artigo 318 do CPP ${ }^{15}$. A ação julgada em 2018 pretendeu garantir a aplicação de uma norma que permitia que mães de crianças de até seis anos pudessem ter acesso à substituição da prisão preventiva pela domiciliar desde 2011, e que ampliou a possibilidade a partir de 2016 para gestantes, mulheres com filhas(os) de até 12 (doze) anos de idade incompletos e homens que sejam os únicos responsáveis pelos cuidados das(os) filhas(os) de até 12 (doze) anos de idade incompletos.

Antes de mais nada, é preciso ressaltar que na prisão domiciliar a pessoa continua presa, não por acaso chama-se prisão! Enquanto para nós, essa observação tem o objetivo de sinalizar que qualquer tentativa de atribuir emancipação com prisão é, no mínimo, temerária, nas palavras do Ministro Relator da ação, Ricardo Lewandowski, ela é mobilizada para garantir a seus pares que a decisão não configura violação ao pacto narcísico:

Ocorreu-me que, talvez, fosse útil esclarecer a todos aqueles que nos assistem que não estamos colocando em liberdade estas mulheres, infelizes mulheres. Elas vão continuar na prisão, só que domiciliar. Vão estar sujeitas a medidas alternativas à prisão. Elas estarão, ainda, sob a custódia do Estado (STF, HC 143641, p. 114).

Diz o artigo 317 do CPP: "A prisão domiciliar consiste no recolhimento do indiciado ou acusado em sua residência, só podendo dela ausentar-se com autorização

\footnotetext{
${ }^{15}$ Diz o artigo 318 do CPP: “Poderá o juiz substituir a prisão preventiva pela domiciliar quando o agente for: (Redação dada pela Lei no 12.403, de 2011). I - maior de 80 (oitenta) anos; (Incluído pela Lei n. 12.403, de 2011). II - extremamente debilitado por motivo de doença grave; (Incluído pela Lei no 12.403, de 2011). III imprescindível aos cuidados especiais de pessoa menor de 6 (seis) anos de idade ou com deficiência; (Incluído pela Lei no 12.403, de 2011). IV - gestante; (Redação dada pela Lei no 13.257, de 2016).V - mulher com filho de até 12 (doze) anos de idade incompletos; (Incluído pela Lei no 13.257, de 2016).VI - homem, caso seja o único responsável pelos cuidados do filho de até 12 (doze) anos de idade incompletos. (Incluído pela Lei no 13.257, de 2016).Parágrafo único. Para a substituição, o juiz exigirá prova idônea dos requisitos estabelecidos neste artigo. (Incluído pela Lei no 12.403, de 2011)".

Art. 318-A: "A prisão preventiva imposta à mulher gestante ou que for mãe ou responsável por crianças ou pessoas com deficiência será substituída por prisão domiciliar, desde que: (Incluído pela Lei no 13.769, de 2018).I - não tenha cometido crime com violência ou grave ameaça a pessoa; (Incluído pela Lei no 13.769, de 2018).II - não tenha cometido o crime contra seu filho ou dependente. (Incluído pela Lei no 13.769, de 2018)".

Art. 318-B: "A substituição de que tratam os arts. 318 e 318-A poderá ser efetuada sem prejuízo da aplicação concomitante das medidas alternativas previstas no art. 319 deste Código. (Incluído pela Lei nº 13.769, de 2018)".
} 
judicial". Ao contrário do que assentou o STF no HC $142.279 / \mathrm{CE}^{16}$, defende-se a tese de que a substituição da prisão preventiva por domiciliar para as pessoas que cumprem os critérios do artigo 318 do CPP não é uma opção para os julgadores. Da mesma forma, mas por caminhos distintos, defendemos que tampouco trata-se de uma escolha para as pessoas em privação de liberdade.

Em relação à magistratura, ainda que a redação do artigo 318 inicie com "Poderá o juiz substituir a prisão", a única interpretação possível em consonância com o texto do artigo 318-A e com um Estado que, em matéria prisional, se configura como um estado de coisas inconstitucional é no sentido de que a concessão só pode depender da apresentação de provas relacionadas aos critérios definidos em lei. Comprovados os critérios, a concessão é obrigatória, assim como a aplicação de outras medidas alternativas ou cautelares diversas da prisão (artigo 319, CPP).

Para as pessoas em privação de liberdade, a substituição da prisão preventiva em domiciliar também não se configura como uma escolha. A cruel e brutal realidade do sistema prisional brasileiro impede que se possa considerar escolha (como exercício de gosto-seleção-predileção) estar presa em uma unidade prisional ou em qualquer outro lugar (por mais precário, por mais que se mantenham os grilhões, as injustiças e os demais processos de morte em vida). $\mathrm{O}$ acesso a medidas de aprisionamento diversas da prisão em unidade prisional não representa escolha, mas um exercício tão precário quanto perverso de subsistir (PIRES, 2015).

Quando nos propomos a perceber os impactos que tais medidas trazem para o aprofundamento do racismo e do sexismo cisheteronormativo, alguns aspectos da decisão saltam aos olhos.

O primeiro deles está relacionado à capacidade de tal medida reforçar o ciclo perverso da violência de Estado através da ideia do aprisionamento como regra e não como exceção. $O$ objetivo anunciado da medida é o de permitir que primordialmente as mães continuem a ser as principais responsáveis pelos cuidados de seus filhos e filhas durante uma fase crucial de suas formações (do nascimento até os 12 anos de idade) ou em razão da necessidade de cuidados especiais (nas hipóteses de dependentes com deficiência).

${ }^{16}$ No HC 142.279/CE, de Relatoria do Ministro Gilmar Mendes, julgado em 2017, o STF entendeu que a substituição da prisão preventiva pela domiciliar nos casos definidos no artigo 318 do CPP deveria dar-se de forma restrita e diligente, verificando-se as peculiaridades de cada caso. 
Para além de uma crítica mais geral e abstrata à cristalização das mulheres nos papéis de cuidado, do ponto de vista concreto e relacionado à maioria das famílias negras brasileiras (que são constituídas primordialmente por mães solo), a manutenção da "prisão", ainda que no âmbito "domiciliar", faz recair sobre essas mulheres um ônus ainda mais desproporcional para garantir o convívio com suas filhas e filhos. Isto porque a medida é pensada de forma desassociada das condições de possibilidade que permitam que tais mulheres possam efetivamente dar conta da subsistência de suas famílias e não implica o Estado nas consequências que gerou nessas unidades familiares quando submeteu essas mulheres a sua custódia.

Ignora-se que o período de prisão configura a descontinuidade de seus lugares de moradia, de suas atividades laborais, a institucionalização de seus filhos e filhas, além do insuportável incremento de despesas em suas unidades familiares (normalmente não nucleares segundo o modelo burguês). Mobilizar a prisão domiciliar como medida de "superação da cultura de encarceramento" é deboche, é um ato de violência que perpetua e aprofunda a incapacidade do Estado em oferecer as condições necessárias para o desencarceramento, no geral, e para que todas as famílias possam se desenvolver em sua plenitude, no concreto.

Em uma leitura historicamente informada, conforme tentamos realizar desde o início do artigo, tal medida converte-se numa espécie de reedição da lei do ventre livre. Aqui, como no período de escravidão oficial, não é uma opção para as pessoas privadas de liberdade perguntar se preferem continuar nas senzalas (ou nas unidades prisionais) longe de suas filhas e filhos ou escravizadas (aprisionadas) em outras condições.

A edição da lei do ventre livre (Lei Rio Branco, de 28 de setembro de 1871) é tratada no âmbito do colonialismo jurídico como uma das normas que promoveram a transição da escravidão oficial para a abolição formal em 1888. Como solucionar o problema da escravidão? Acabando com ela? Não, promovendo novas formas de servidão (lei do ventre livre e lei dos sexagenários, por exemplo) com roupagem de transição para a liberdade, mantendo intactos os direitos da zona do ser.

No mesmo sentido, disse o STF na ementa do HC 152.932-SP que necessitamos superar o superencarceramento. Promovendo o desencarceramento? Não, criando novas formas de gestão da prisão. Dessa maneira, apesar de apartados no tempo, esses institutos guardam indiscutivelmente grande conexão entre si. Afinal, é preciso ressaltar 
que o fim da escravidão no século XIX parecia aos olhos da branquitude tão descabido, absurdo e amedrontador ${ }^{17}$ quanto pode parecer hoje à luta pelo desencarceramento como sinônimo de promoção da liberdade.

Assim como as decisões que utilizaram o CPP para permitir a aplicação da prisão domiciliar nas hipóteses do artigo 318 foram festejadas como representação de uma medida progressista e de enfrentamento à barbárie do sistema prisional brasileiro, a lei do Vente Livre foi festejada como uma medida de emancipação da população escravizada (CARNEIRO, 1980).

Nos termos da lei, o Império brasileiro dizia nascer livre o filho da mulher escrava a partir da data de promulgação da norma, 28 de setembro de 1871. Por liberdade entendia-se que as crianças ficariam sob a autoridade dos senhores de suas mães que, por sua vez, seriam os únicos a ter direito a escolher entre, após as crianças atingirem oito anos de idade: (a) receber uma indenização do Estado e entregar a criança para ser institucionalizada, ou (b) utilizar-se de seus serviços (gratuitamente, por esperado) até completarem 21 anos.

Por oportuno e como postula o melhor juízo, o direito do senhor da mulher escravizada era transmissível por sucessão e, no caso de venda da mulher escravizada, o novo senhor sub-rogava-se aos direitos do antecessor. Já a possibilidade desse menor (termo usado na lei, em 1871) remir-se do ônus de servir ficava condicionada ao pagamento de indenização ao senhor de sua mãe. O Estado, por sua vez, quando

\footnotetext{
17 Para exemplificar, utilizamo-nos de dois trechos da pesquisa de Marcos Queiroz (2017), baseada nos Anais da Constituinte de 1823, através da fala de dois Deputados. A primeira que gostaríamos de ressaltar é a do Deputado Constituinte Alencar, que na discussão sobre cidadania disse: "Digo que o artigo é conforme aos princípios de justiça universal porque ainda que pareça que deveríamos fazer cidadãos brasileiros a todos os habitantes do território do Brasil, todavia não podemos seguir rigorosamente este princípio, porque temos entre nós muitos que não podemos incluir nessa regra, sem ofender a suprema lei da salvação do estado. É esta lei que nos inibe de fazer cidadão aos escravos, porque além de serem propriedade de outros e de se ofender por isso este direito se os tirássemos do patrimônio dos indivíduos a que pertencem, amorteceríamos a agricultura, um dos primeiros mananciais da riqueza da nação, $e$ abriríamos um foco de desordens na sociedade introduzindo nela de repente um bando de homens que saídos do cativeiro mal poderiam guiar-se por princípios da bem entendida liberdade (QUEIROZ, 2017, $\mathrm{p}$. 159). A segunda, do Deputado Costa Barros recomendando ao governo a pronta extinção do quilombo "denominado Guandú", solicitação aprovada dois dias depois pelos demais membros da Constituinte: "Sr. Presidente, é chegada a hora das indicações e eu tenho a fazer uma para que a Assembleia a tome em consideração: é geral o clamor em toda esta cidade pelo sem número de escravos fugidos [...] não conheço uma só casa das da minha amizade que não tenha escravos fugidos: e consta-me que há quilombos de 100, e até asseveram de 1000 escravos fugidos: é uma força que está engrossando ao pé da cidade, e que pode vir a dar cuidado: e é necessário tomar isto em consideração [...]. Vão engrossando esses conluios todos os dias e não se atende às consequências que dele podem resultar. Peço, portanto, que se oficie ao governo para que faça prontamente diligência de extinguir estes quilombos [...] requeiro que o governo mande uma força tal, que não fique de novo maltratada, e consiga a total extinção daqueles ajuntamento" (QUEIROZ, 2017, p. 154).
} 
pagasse a indenização exigida pelo senhor da mulher escravizada pelo seu filho ou filha, o(a) manteria institucionalizado(a) em unidades próprias, utilizando-se gratuitamente dos seus serviços até a idade de 21 anos, ou os(as) entregaria a associações que passariam a exercer sobre eles(as) as mesmas prerrogativas.

É de racismo que estamos falando quando falamos de cultura do encarceramento. O objeto da ADPF 347 -DF é entendido pelo Ministro Marco Aurélio como: "pauta impopular, envolvendo direitos de um grupo de pessoas não simplesmente estigmatizado, e sim cuja dignidade humana é tida por muitos como perdida, ante o cometimento de crimes" (STF, ADPF 347-DF, p. 21). Tal posicionamento só faz sentido para quem está imune a esses processos e pretende manter o pacto narcísico que sustenta esse privilégio ou para quem imagina que, endossando esse discurso, pode aproximar-se desse lugar de "imunidade". Aqui, é importante lembrar que há quem cometa crimes e não tenha a sua humanidade questionada como tantas (os) outras(os) que são desumanizadas(os) independente de suas condutas serem consideradas ilícitas pelo ordenamento jurídico brasileiro.

É o racismo que torna essa causa "impopular" e faz com que as medidas de promoção de condições menos degradantes para a população negra sejam institucionalmente despotencializadas e respaldadas intersubjetivamente. Em 1871 como em 2018, o avanço possível foi sofisticar a ação genocida do Estado, pela gestão multifacetada do aprisionamento.

Como os requintes de crueldade se avolumam, muitos são os exemplos explícitos de como o sexismo cisheteronormativo ocorre na atuação do STF. Vamos, contudo, apresentar apenas duas hipóteses, que se justificam por sua contundência: a primeira demonstrando o (des)valor do testemunho das mulheres e a segunda que caracteriza a completa irrelevância da mulher no processo de tomada de decisão envolvendo a sua (não)liberdade.

Ao avaliar a necessidade do cumprimento de um dos requisitos que o CPP estipula para substituição da prisão provisória pela domiciliar - demonstração de que as crianças dependem dos cuidados das mães - entendeu inicialmente o Ministro Relator, Ricardo Lewandowski:

Para apurar a situação de guardiã dos filhos da mulher presa, dever- se-á dar credibilidade à palavra da mãe. Faculta-se ao juiz, sem prejuízo de cumprir, desde logo, a presente determinação, requisitar a elaboração de laudo social para eventual reanálise do benefício (STF, HC 143641, p. 57). 
Contrariamente, se manifestou o Ministro Dias Toffolli: "Penso, portanto, com a vênia de estilo, que dar credibilidade, pura e simplesmente, à palavra da mãe presa para apurar a situação de guardiã de seus filhos não se mostra suficiente" (STF, HC 143641 SP, p. 79). Reforçou, em seguida: "é uma preocupação que eu realmente tenho; quer dizer, a palavra da mãe não ser tomada de maneira absolutamente verdadeira e objetiva. Talvez, aqui, coubesse uma análise social, uma análise psicológica dessa situação" (STF, HC 143641 SP, pp. 115-116).

Diante da controvérsia, o Ministro Relator:

\begin{abstract}
No primeiro momento, temos que dar credibilidade, assim como fazemos nos crimes sexuais: A palavra da vítima é muito importante. Se, depois, provar-se que ela não é guardiã, ela perde o benefício. Entretanto, no primeiro momento, tem que se dar o benefício da dúvida, em homenagem ao bem-estar da criança. Entretanto, também estou aberto, se Vossa Excelência quiser subtrair este paragrafo, estou pronto a fazê-lo, em benefício de chegarmos a uma solução harmônica relativamente a este caso" (STF, HC 143641 SP, p. 116).
\end{abstract}

Foi nesses termos que dois Ministros homens decidiram sobre o valor da manifestação de uma mulher que, submetida à prisão em um ambiente reconhecido como próprio a um estado de coisas inconstitucional, postula tão somente a aplicação do CPP que determina a substituição da prisão provisória pela prisão domiciliar.

A segunda hipótese, que foi explicitada de forma mais contundente no voto do Ministro Edson Fachin, é aquela que anula por completo a mulher privada de liberdade da análise que pode ensejar a aplicação do artigo 318 do CPP. Nas palavras do Ministro Fachin:

[...], defiro a ordem de habeas corpus coletivo exclusivamente para dar interpretação conforme aos incisos IV, V e VI do art. 318 do Código de Processo Penal, a fim de reconhecer, como única interpretação constitucionalmente adequada, a que condicione a substituição da prisão preventiva pela domiciliar à análise concreta, justificada e individualizada, do melhor interesse da criança, sem revogação automática das prisões preventivas já decretadas (STF, HC 143641 SP, p. 140).

O mesmo ministro que referencia a Declaração de Kiev, que determina que deve ser compensada a flagrante desigualdade de gênero a que estão sujeitas as mulheres no estabelecimento da política pública e do descumprimento de regras mínimas de tratamento das mulheres encarceradas, diz que a única interpretação conforme é aquela baseada no melhor interesse da criança. 
Vê-se, portanto, que as imbricações das condicionantes de gênero e raça no Brasil acabam por solapar os objetivos declarados de desencarceramento sustentados pela Corte Suprema na declaração do estado de coisas inconstitucional. A forte identificação dos ministros com o status quo inviabiliza a aplicação mais abrangente da norma, violando os direitos de milhares de mulheres.

Em pretuguês (GONZALEZ, 1988), reconhecemos que tanto a ADPF 347-DF quanto as demais ações relacionadas à concessão de prisão domiciliar ${ }^{18}$ ampliaram o vocabulário jurídico de denúncia do racismo e do sexismo cisheteronormativo no âmbito das instituições do sistema de justiça criminal. O que pretendemos sinalizar, em razão do compromisso assumido de chamada à responsabilidade pontuado no início do artigo, é que o manejo pelo STF e pelos demais órgãos do sistema de justiça desse vocabulário se dá via pacto narcísico (BENTO, 2002). Nesse sentido, o que poderia significar um compromisso com a liberdade e a vida é revestido pelo solipsismo branco (OYÈWÚMI, 2002) das elites brasileiras para oferecer um escudo camuflado de argumento jurídico que mantém a liberdade e o acesso à legalidade como atributos exclusivos da zona do ser. O que se observa é que, no horizonte do genocídio, a liberdade é produto não disponibilizado no mercado dos indigentes que povoam a zona do não ser, sendo a dor e a degradação as sentenças impostas pela branquitude que se perpetua nos rituais do Judiciário no Brasil.

\section{Considerações Finais}

A forma como se deu o reconhecimento do estado de coisas inconstitucionais pelo STF e a maneira como se trata dos direitos das mães no contexto da prisão domiciliar são ilustrativos da forma como o poder público no Brasil tem gerido o genocídio negro.

Aqui, é importante destacar que na dilaceração imposta às comunidades negras nessa engenharia de punição, os efeitos mais perversos são sentidos pelas mulheres. $O$ encarceramento masculino sobrecarrega desproporcionalmente a vida das mulheres que precisam subsistir (e garantir a subsistência de muitas/os) em meio a um ambiente de vulnerabilidade econômica, familiar e psicológica acirrado pelo

\footnotetext{
${ }^{18}$ Sobre esse tema, nos detivemos mais especificamente em relação ao HC 143641 SP, fazendo referências pontuais a outros julgados no mesmo sentido, como por exemplo o HC 152.932 SP e HC 142.279 CE, todos julgados pelo Supremo Tribunal Federal.
} 
aprisionamento de seus filhos, irmãos, companheiros e netos. Efeitos que, apesar da sua concretude e centralidade para a zona do não ser, sequer passaram pela análise do STF quando se manifestou sobre o estado de coisas inconstitucional.

Se o encarceramento masculino é devastador para as famílias negras, o encarceramento feminino, por sua vez, acaba por inviabilizar a nossa permanência enquanto família, comunidade e povo. Para as mulheres, cis ou trans, que serão submetidas às masmorras carcerárias brasileiras, as violências raciais, de classe, de gênero e sexualidade que conhecem serão potencializadas pela privação de liberdade em um ambiente pensado para controlar e matar aos poucos aqueles cuja masculinidade foi reduzida à condição de macho.

A superlotação, a falta de material de higiene pessoal e meios de manutenção da saúde em geral, a ausência de alimentação adequada, a inexistência em muitas unidades de oferta de trabalho ou estudo para remissão da pena, o não acesso à justiça ganham novas dimensões quando o corpo que vai vivenciar essas violações é um corpo feminino. Tudo o que é precário/inexistente nas unidades masculinas, torna-se precário/inadequado/insuficiente/inexistente nas unidades femininas ou mistas.

Diante desse cenário, o próprio STF reconhece como exagerada e irrazoável a imposição de prisões provisórias a mulheres pobres e vulneráveis, em decorrência de excessos na interpretação e na aplicação da lei penal e processual penal, mesmo diante da existência de outras soluções, de caráter humanitário, abrigadas no ordenamento jurídico vigente.

Desenhado esse horizonte, só se pode concluir que o racismo, com suas correlatas dimensões de gênero e sexualidade, é um fenômeno tão forte no Brasil que mesmo quando o órgão de cúpula do Poder Jucidiário, o STF, se manifesta no sentido da necessidade de "superar tanto a arbitrariedade judicial quanto a sistemática exclusão de direitos de grupos hipossuficientes, típica de sistemas jurídicos que não dispõem de soluções coletivas para problemas estruturais 19 ", o que produz tamanha ilegalidade/inconstitucionalidade permanece em pleno funcionamento e isso não gera nem comoção popular, tampouco medidas judiciais de enfrentamento.

A fragilidade das instituições no atual contexto político exige uma tomada de postura assertiva. $\mathrm{O}$ assédio de forças conservadoras aos estamentos do poder é em grande parte viabilizado pelo pacto histórico da branquitude para a manutenção de seus

${ }^{19}$ Ementa do HC 143.641-SP, item XIII. 
privilégios. Nesse sentido, a afirmação da democracia no Brasil só se viabiliza com a ruptura dos acordos políticos que têm condenado a população negra à indignidade do encarceramento e da morte. É por isso que, no lastro das lentes dos feminismos negros que nos guiam, denunciamos a chancela e a participação ativa do Judiciário na conformação desse estado de dor, advogando pelo fim da barbárie travestida de civilidade nos meandres do Direito.

\section{Referências Bibliográficas}

ALVES, Dina. Rés negras, juízes brancos: uma análise da intersecionalidade de gênero, raça e classe na produção da punição em uma prisão paulistana. Revista CS, Número 21, p. 97 - 120, Enero - Abril, 2017.

BENTO, Maria Aparecida Silva. Branqueamento e Branquitude no Brasil. In: Psicologia social do racismo - estudos sobre branquitude e branqueamento no Brasil / Iray Carone, Maria Aparecida Silva Bento (Organizadoras) Petrópolis, RJ: Vozes, 2002, p. 25-58.

CARNEIRO, Édison. A Lei do Ventre-livre. Afro-Ásia, n. 13, 1980.

CARNEIRO, Aparecida Sueli. A construção do outro como não-ser como fundamento do ser, Tese de Doutorado, USP, São Paulo, 2005.

COLLINS, Patricia Hill. Pensamento Feminista Negro: conhecimento, consciência e a política do empoderamento. Tradução de Jamille Pinheiro Dias. $1^{\text {a }}$ ed. São Paulo: Boitempo, 2019.

COSTA, Alexandre Bernardino. Ensino Jurídico: disciplina e violência simbólica. Dissertação. (Mestrado em Direito), Universidade Federal de Santa Catarina, Florianópolis,1992.

CURIEL, Ochy. "De las Identidades a las Imbricación de las opresiones: Desde La experiencia." In Encrespando. Anais do I Seminário Internacional: Refletindo a Década Internacional dos Afrodescentendes (ONU, 2015-2024) / FLAUZINA, Ana; PIRES, Thula (org.). Brasília: Brado Negro, 2016, p. 75-89.

Construindo metodologias feministas a partir do feminismo decolonial. In Pensamento feminista hoje: perspectivas decoloniais. Org. Heloisa Buarque de Hollanda. $1^{\mathrm{a}}$ Ed. Rio de Janeiro: Bazar do Tempo, 2020. p. 120-138.

FLAUZINA, Ana Luiza Pinheiro. Corpo negro caído no chão. O sistema penal e o projeto genocida do Estado brasileiro. Rio de Janeiro: Contraponto, 2008. 
GONZALEZ, Lélia. Primavera para as Rosas Negras: Lélia Gonzalez em primeira pessoa. Coletânea Organizada e editada pela União dos Coletivos Pan-Africanistas (UCPA). Diáspora Africana, 2018.

A categoria político-cultural de amefricanidade. Tempo Brasileiro, v. 92, $n$. 93, 1988. p. 69-82.

. Racismo e sexismo na cultura brasileira. Revista Ciências Sociais Hoje, v. 2, n. 1, p. 223-244, 1984.

HARTMAN, Saidiya. Scenes of Subjection: Terror, Slavery, and Self-Making in Nineteenth-Century America. New York, NY: Oxford University Press, 1997.

NASCIMENTO, Beatriz. Beatriz Nascimento, Quilombola e Intelectual: possibilidade nos dias da destruição. $1^{\text {a }}$ ed. Diáspora Africana: Editora Filhos da África, 2018..

OYĚWÙMÍ, Oyèrónkẹ. Conceptualizing gender: the eurocentric foundations of feminist concepts and the challenge of African epistemologies. Jenda: A Journal of Culture and African Women Studies, 2.1, 2002, p. 1-9.

PIRES, Thula. Racializando o debate sobre direitos humanos. SUR - Revista Internacional de Direitos Humanos. V. 15, n. 28., dez. 2018. p. 65-75.

Do ferro quente ao monitoramento eletrônico: controle, desrespeito e expropriação de corpos negros pelo Estado Brasileiro. In: Ana Luiza Pinheiro Flauzina; Felipe da Silva Freitas. (Org.). Discursos negros: legislação penal, política criminal e racismo. 1ed.Brasília: Brado Negro, 2015, v. 1, p. 44-82.

QUEIROZ, Marcos Vinícius Lustosa. Constitucionalismo brasileiro e o Atlântico Negro: a experiência constitucional de 1823 diante da Revolução Haitiana. 2017. 200 f., il. Dissertação (Mestrado em Direito)—Universidade de Brasília, Brasília, 2017.

ROCHA, Luciane. Morte íntima: a gramática do genocídio antinegro na Baixada Fluminense. In: FLAUZINA, Ana; VARGAS, João. Motim: os horizontes do genocídio antinegro na Diáspora. Brasília: Brado Negro, 2017.

SANTOS. Élida de Oliveira Lauris dos. Reforma global da justiça, pluriversalismo e legalidade subalterna: Reflexões teóricas e empíricas a partir de uma ecologia de justiças no Brasil, em Moçambique e em Portugal. A REVISTA CRONOS, v. 16, p. 87-113, 2017.

VARGAS, João Helion Costa, A Diáspora Negra como Genocídio, REVISTA DA ABPN, no. 2, Ju.- Out. 2010, p.31-56.

The Denial of Antiblackness: Multiracial Redemption and Black Suffering. Minneapolis, MN: University of Minessota Pres, 2018.

WILDERSON III, Frank. Gramsci's Black Marx: Whiter the Slave in Civil Society? Social Identities, v.9, n.2, 2003, pp.225-240. 
Red, White, and Black: Cinema and the Structure of U.S. Antagonism. Durham, NC: Duke University Press, 2010.

ZAFALLON, Luciana. A Política da Justiça: Blindar as Elites, Criminalizar os Pobres. São Paulo: Hucitec, 2018, 438p.

Sobre as autoras

\section{Ana Flauzina}

É mulher preta que aposta nos movimentos: da vida e das batalhas. Doutora em Direito pela American University Washington College of Law e com pós-doutorado pelo African and African Diaspora Studies Department na University of Texas at Austin. Professora da graduação da Faculdade de Educação da UFBA e da pós-graduação de Direito da UFBA. E-mail: anaflauzina@yahoo.com.br. ORCID: https://orcid.org/0000-00029995-7675.

\section{Thula Pires}

É mulher preta de axé, mãe da Dandara e bailarina. Doutora em Direito Constitucional pela PUC-Rio, professora da graduação/pós-graduação em Direito e coordenadora do NIREMA (Núcleo Interdisciplinar de Reflexão e Memória Afrodescendente) na mesma Instituição. Professora Visitante no African Gender Institute, University of Cape Town (CAPES/PRINT/2020). E-mail: thula@puc-rio.br. ORCID: https://orcid.org/0000-0003-2138-5483.

As autoras contribuíram igualmente para a redação do artigo. 